\title{
Dyslexia and oral skills: A student's journey
}

\section{Rose Stanton}

Otago Polytechnic, New Zealand

Email: Rose.Stanton@op.ac.nz

\begin{abstract}
This single-case study aimed to identify specific themes and learning strategies that were evident in the Tertiary Learning Advisor consultations, which helped one occupational therapy student to achieve success with oral skills. The student was assessed with dyslexia in her second year of study, after having failed her oral assessments. The case outlines a number of individual learning sessions over a period of three years and presents the student's view of what strategies were significant. The study uses three sources of data. The first is an interview with the student a year after completing her degree. The second is the Learning Advisor's notes written routinely for each consultation, and the third is the student's Cognitive and Educational Assessment. The student not only mastered the viva voce (oral assessment), but achieved a job interview and subsequent employment as an occupational therapist. The findings include a range of understandings of how dyslexia informs self-identity, and outlines some creative ways of working with voice to reduce stress and anxiety.
\end{abstract}

Key words: tertiary education, learning advising, dyslexia, oral assessment, viva voce

\section{Introduction}

Learning Advisors (LAs) work in a student-focused way, with students from diverse backgrounds, in an adult learning context. LAs actively encourage students academically, and aim to impart strategies for managing their own learning and becoming independent learners. They also encourage self-confidence in learners, assist with oral skills, provide pastoral and personal support, and help to demystify the academic system (Cameron, 2012). There is a growing body of research published by the Association of Tertiary Learning Advisors Aotearoa/New Zealand (ATLAANZ).

This case study outlines the three-year journey of an occupational therapy student, as she developed strategies to achieve success with the viva voce (living voice) assessments of her course. Having failed these assessments in her second year, she enlisted the help of a tertiary 
Learning Advisor (LA) to work towards overcoming the difficulties, and during that same year was formally assessed as having dyslexia. This study identifies and analyses themes from three sources of data: the LAs notes made following each session; the student's Cognitive and Educational Assessment; and an interview with the student some months after course completion. The aim was to ascertain key elements of the work with the LA that helped the student to achieve positive outcomes in academic oral assessments. The paper contributes to the discussions of issues for adults identified as dyslexic and to the growing awareness of positive dyslexia.

\section{Dyslexia support in tertiary education}

Despite dyslexia being a well-researched and accepted condition internationally, in New Zealand it has only been recognised within education since 2007. This situation persisted partly due to a lack of agreement on the terminology of the condition (Blundell, 2006). Dyslexia has been commonly thought of as a difficulty with reading, writing and spelling, as these are the most obvious symptoms. Dymock and Nicholson (2012) took the view of persistent literacy difficulties due to difficulties in learning to decode and encode words. Others take a broader view: It is now accepted, however, that dyslexia is a heterogeneous condition with a range of symptoms; consequently, there are as many differences between dyslexics as between non-dyslexics. The range of symptoms associated with dyslexia also includes working memory problems, poor organisational skills, slower verbal and cognitive processing speed and slower automaticity (Ako Aotearoa and Primary ITO, n.d.). Due to the complex range of symptoms it may not be easy to identify learners who are dyslexic.

Partly due to the historic lack of agreement on terminology, learners may arrive at tertiary institutions without knowing they have a learning disability such as dyslexia (Jamieson \& Morgan, 2008). This can create significant personal challenges and distress in the process of facing up to their own specific ways of learning, which consequently impacts on the support services available, in terms of time and expertise. In addition, there is little research around the impact on adult learners of having their dyslexia recognised as late as their tertiary studies. Jamieson and Morgan suggested that dyslexia has an effect on many of the wider aspects of learning: memory, oral skills, organisation, and affective factors such as confidence and self-belief. 
Dyslexia can affect up to $10 \%$ of the population, and increasing numbers of tertiary students are identified as having dyslexia and other learning difficulties. People with dyslexia often have poorer outcomes in areas such as education, employment and mental health (Ako Aotearoa and Primary ITO, n.d). In many tertiary educational environments, dyslexia is classified as a form of disability. Through the disability support services, students with evidence of dyslexia are provided with support such as extra time, technological services and access to other additional support (NCVER, 2015; Ako Aotearoa and Primary ITO, n.d.; Styles et al., 2018). The additional support may be in the form of Learning Advisors, or specialist dyslexia tutors (Jamieson \& Morgan, 2008).

Many students arrive at tertiary institutions without a formal dyslexia assessment, while some dyslexics who managed to cope at school now find they are facing new or more extreme challenges (Jamieson \& Morgan, 2008). This may result in lost time while assessment processes occur, or while the student comes to terms with the new diagnosis. The dyslexia assessment process ranges from an introductory assessment or indication (Moody, 2004) to a comprehensive assessment by an educational psychologist or trained practitioner (Ako Aotearoa and Primary ITO, n.d.; Jamieson \& Morgan, 2008). The Dyslexia Adult Screening Tool (DAST) has recently been endorsed as the preferred method by Primary ITO, New Zealand's umbrella industry training organisation (Styles et al., 2018). It is significant that identifying the need for assessment is critical to this process yet, at times, this does not occur until after the student has already experience failure or poor performance, sometimes because the student is reluctant to disclose the difficulties they are having.

According to the Australian Education and Training guidelines (NCVER, 2015), institutionallevel learning support services often rely on the students themselves to disclose their illness or disability. McPheat (2014) discussed issues for student nurses on clinical placement in the workplace (p.45) around disclosure of dyslexia, and the fear that it might result in discrimination and ridicule. However, only when students disclose dyslexia, and come to terms with what it means to them, can institutional-level support be made available. 
Nevertheless, there is limited provision for the specific psychological challenges that may be present for those with dyslexia or other learning difficulties. People with dyslexia have poorer outcomes in education and mental health, and they are often lacking in confidence and self-belief. Therefore, despite being a highly studied population, there is a need for more subjective personal accounts of being dyslexic (Burden, 2005). Burden researched concepts including socio-cultural theory, motivation, self-efficacy, locus of control and learned helplessness, and extended the discussion to the connection between learned helplessness and depression in people with dyslexia. He stated that dyslexics may avoid tasks such as reading and writing and "expend less effort on such tasks, [...] lack resilience, and [...] be more vulnerable to stress and anxiety in academic situations" (p.23). Burden claimed that people have more success if they believe in their own capabilities (p.21). Smith (1982) stated that self-understanding is a key part of equipping the student for further learning. One way of encouraging this for students with dyslexia would be to create opportunities for them to find out about their learning styles, strengths and weaknesses, and to assist them to understand how learning takes place.

The Australian National Centre for Vocational Education Research (NCVER, 2015) suggested that developing and using stress management strategies may be helpful for students with disabilities. This is supported by Tummers (2013), who outlined the stressors affecting college students, including those with dyslexia (p.9), and offered multiple helpful strategies for managing stress. Amongst these are the strengths-based approach which focuses on practices such as "being optimistic, believing in our abilities, increasing our happiness and motivation, and tapping into our unique intelligences" (p.20). These are also characteristics of the Positive Psychology movement (Seligman, 2002). Seligman's research has led the way to a well-being theory, and Positive Psychology has been adapted to positive dyslexia to help learners become aware of their strengths (Ako Aotearoa and Primary ITO, n.d.; Nicolson, 2013). McPheat (2015) supported the positive dyslexia approach in helping nursing students to identify their strengths. Many positive attributes such as strong visual and spatial skills, good verbal communication skills, manual physical dexterity, creativity and problem-solving skills are outlined in Ako Aotearoa and Primary ITO (n.d.). Finally, if dyslexia can be seen as "another human variation rather than a negative feature, this may help people to accept and embrace their learning difficulty" (McPheat, 2015, p.47). Clearly, a range of strategies and 
support is required within tertiary education to work with the range of learners who present with dyslexia.

\section{Oral skills and oral assessments}

There may be unexpected difficulties for dyslexic students when they are faced with oral assessments. For example, Hughes (2002) discusses the status of speech in society and in linguistic theory. She states that there are difficulties inherent in the teaching of speaking and maintains that the spoken form of language is under-researched. This may be due to the comparative lack of stability of the spoken form, and the fact that spoken discourse is context dependent; unplanned; transient; oral/aural, and dynamic compared to written discourse (p.10). Blakemore and Frith (2005) maintain that written language is a "subplot of the development of spoken language" (p.87). They find it plausible that developmental issues for sound processing and speech may be a large contributor to children having difficulties learning to read and write. This may help to clarify why some dyslexic students also have difficulties with oral skills.

Despite written assessment being predominant, tertiary educational institutions use oral assessments as part of their course requirements, utilising viva voce and role-play, as well as presentation skills and fieldwork placements. The viva is commonly used as part of the $\mathrm{PhD}$ process to support, and examine, the candidates' thesis (Carter, Datt \& Donald, 2012). In addition, the viva is used in the author's institution as an assessment method in the occupational therapy programme. The use of the viva is well-supported in tertiary education, with Scott (2017) considering the viva a powerful type of assessment. In addition, Hargreaves (2012) suggested that role-play is an effective method of learning for students training to work in practical courses (p.152). This is true in the author's institution, where Stanton (2007) reported on using role-play to develop students' oral skills for fieldwork placement in nursing and occupational therapy (p.31). Oral presentations skills are similarly needed for design studio assessment, and Anderson and Shepherd (2006) outlined a communication elective at the Royal Melbourne Institute of Technology (RMIT) for teaching these skills. The RMIT course focused on identification and analysis of performance skills using strategies from acting such as breathing and voice, tone and attitude, body language and presence (p.103). Stanton and Wilson (2013) outlined the benefits of experiential and creative work in expressive arts therapy to help with personal development and gaining 
confidence in the use of voice. Such studies highlight the merits of oral assessments in tertiary institutions where students are training in roles that require confident presentation skills.

In addition to the complexities of speech and performance above, many students have anxiety related to public speaking (Tummers, 2013). Efforts can be made to reduce this and to develop skills to become better at presentations and interviews (Anderson \& Shepherd, 2006; Hammond, 2014). For example, Brain Gym ${ }^{\circledR}$, developed by Dennison and Dennison (1989), teaches ways of relaxing and integrating the body and the mind in order to perform better, including exercises for improving both verbal and nonverbal communication skills. Similarly, Positive Psychology (Seligman, 2002) reflects the understanding that relaxation and stress management will aid confidence.

Aside from the usual rigours of public speaking, people with dyslexia may have additional requirements when processing speech and oral language; therefore, despite the commonly held view that oral skills may be a better alternative to writing, this may not always be the case for individuals with dyslexia. In a study on the use of study skills support among 136 male students in 17 British higher education institutions in the UK, Mortimore and Crozier (2007) found that $24 \%$ of the dyslexia group reported difficulties expressing ideas orally, compared with $10 \%$ of the comparison group. Therefore, there is clearly a need for teaching oral communication skills at tertiary level for students with dyslexia.

This case study, of one occupational therapy student meeting the challenges of viva voce assessments, seeks to contribute to this body of work.

\section{The student participant}

The participant, Jessica (a pseudonym), was in her second year of occupational therapy when she was referred to the Learning Advisors at Student Success, because she had failed the oral assessment or viva voce, for the course entitled Integration of Practice. Jessica had passed all other components of the programme in her first year. Furthermore, despite having some extra academic support at high school with oral skills, she had not been identified as dyslexic. At first she was reluctant to meet with a Learning Advisor and, at the end of the first cycle of work, had still not passed the assessment. However, a working relationship gradually became 
established, whereby she worked with the Learning Advisor for eight to ten sessions a year over the following two years. On degree completion, Jessica not only passed the oral assessments, but also won a job interview and was offered the position.

\section{Methodology}

This is a single case study: It investigates a "contemporary phenomenon within its real-life context" (Yin, 2003, p.13), and is useful in this instance as an in-depth exploration in order to explain certain phenomena (Hammond \& Wellington, 2013). This case study is longitudinal, and followed the journey of one tertiary student over a period of three years. In order to provide triangulation and appropriate rigour (Yin, 2011) the study used three sources of data:

(1) a recorded and transcribed interview with the student, one year after course completion;

(2) session notes written by the Learning Advisor (LA) after each session over the three year period, and

(3) the student's Cognitive and Educational Assessment (dyslexia report), conducted by an educational psychologist during the student's second year of study.

The Otago Polytechnic Ethics Committee approved the research (\#682), and the participant gave written required consent for the use of the information used in the study.

\section{Data gathering and analysis}

The researcher conducted the interview the year following Jessica's course completion. To satisfy ethical requirements, a neutral party, the researcher's manager, contacted Jessica to obtain free consent and avoid any possible coercion. The interview was semi-structured with open questions, which were sent to Jessica prior to the interview. Giving prior notice was considered important, as part of the study related to the stressful nature of oral interviews. The interview took place in a comfortable setting, covered sixteen questions, and lasted about 40 minutes. The resulting discourse was transcribed fully, followed by an inductive process of studying, reducing, and analysing the text (Seidman, 2013), in order to identify and classify themes to inform the narrative and the research discussion.

The Learning Advisor's original notes, written during or after each of the sessions, were entered into a separate table for each year. The notes were reduced using an inductive 
approach by "marking what is of interest in the text" (Seidman, 2013, p.120). That material was then coded and categorised in order to find emerging learning activities and teaching functions (Hammond \& Wellington, 2013; Seidman, 2013).

The full text of Jessica's Educational Assessment by an educational psychologist was made available, with her permission. Evidence from its diagnosis of dyslexia provided a source of data for triangulation, and to inform the analysis and discussion.

\section{Findings}

\section{Participant interview}

The analysis of the interview with Jessica revealed the following strategies introduced during her sessions with the LA had been helpful to her:

- Brain Gym® (Educational Kinesiology)

- memory strategies

- calming and grounding strategies

- picking out key words and questions

- being helped to stay on task and stay focused

- taking turns and maintaining eye contact

- writing out notes using handwriting.

These strategies comprise three main categories: stress reduction, personal awareness or selfknowledge, and language or communication skills. Within the wider practice of Learning Advisors' work, these can be seen as sub-skills of study skills and language development (Cameron \& Catt, 2014; Simpson, 2002; Smith, 1982; Tamblin \& Ward, 2006). During the sessions, Jessica also became aware of the helpfulness of using her own handwriting (for memory cards) as opposed to "reading off print". Although written language is not within the scope of this project, assistive technology ${ }^{1}$ is making a considerable difference for many students with dyslexia.

\footnotetext{
${ }^{1}$ Further examples of technological aids and wider institutional support are available from Styles et al. (2018) and Ako Aotearoa: https://ako.ac.nz/knowledge-centre/interventions-for-learnerswithdyslexia/best-practice-guide-tutors-and-teachers/
} 


\section{Learning advisor's notes}

The reduction and coding of the Learning Advisor's written notes identified the following course of actions and interventions during all three years of the work. They are presented here in the order they were extracted from the notes during the first year:

- conducting a needs analysis

- co-creating a learning plan

- observing and containing distress and disappointment

- teaching tools for anxiety reduction (breathing, visualisation and Brain Gym®

- giving information (Stress management, memory, learning styles, language and the brain)

- assessing needs and evaluating progress

- teaching viva practice skills, such as interview skills

- teaching oral skills, such as voice tone and speed

- planning and administration

- giving and receiving positive messages of gratitude and progress.

Two further categories were identified, once each, in two separate years:

- liaising with other services (for dyslexia assessment and support) and

- facilitating student self-assessment (Bourke, 2015).

The findings together indicate that the key records of the session included teaching practice such as needs analysis, learning plans, feedback, evaluation and administration. The specific skills required were attended to by teaching appropriate language skills and study skills. Affective factors that impinge on learning were also identified, resulting in work on stress reduction and anxiety management, which was confirmed in the student's recall of the usefulness of the sessions.

\section{Cognitive and educational assessment}

Jessica was administered the WJ 111 general Intellectual Ability-Extended Scale (GIA Ext), which includes two measures of each of seven cognitive factors: Comprehension-Knowledge, Long-term Retrieval, Visual-Spatial Thinking, Auditory Processing, Fluid Reasoning, Processing Speed and Short-Term Memory. Although Jessica gave permission to use the full assessment for the research project, it was considered beyond the aims of this article to 
include an analysis of the individual test results. Nevertheless, this summary supports the overall finding that the student "has dyslexia":

- The results showed that, according to the Relative Proficiency Index (RPI) scores, Jessica tested low-to very low in two areas: Short term memory and processing speed (including cognitive fluency).

- There was only one area of comprehension-knowledge in oral language that tested slightly low: "understanding directions".

- In contrast, story recall and oral comprehension were in the average range of proficiency.

These findings indicate that the manifestation of Jessica's oral skills difficulties were primarily to do with brain function and processing, rather than a deficit in oral language skills or comprehension. Specific Learning Disability (SLD) has no clearly defined characteristics and may show up as unexpected difficulties in only some aspects of learning (Tunmer \& Chapman, 2005; Styles et al., 2018).The results build a profile of the challenges Jessica was having, and offer some insight into the Learning Advisor's interventions.

\section{Discussion}

The work and role of Learning Advisors are, at times, misunderstood. From working in the margins (Radloff, 2006) to lack of clarity and lingering shadows around the role (Gao \& Reid, 2015; Golding et al., 2015). Research on Learning Centre practice, conducted by Cameron and Catt (2014) and Cameron (2018), indicates the continuing need to describe our services and report on our effectiveness. This project attempted to highlight one aspect of our service through an in-depth study of one student's learning experience and collaborating with her to develop the personal and academic skills required for her to succeed. A major catalyst for undertaking the study was the positive feedback (in the form of thanks and gratitude) from Jessica during the learning process, and her insistence that the work with the Learning Advisor had been the primary academic support available to her. This study was an opportunity to formalise the informal feedback that is so often received, but so difficult to quantify. 
Contrary to the majority of evidence that highlights difficulties for people with dyslexia in processing written texts, the findings of this project indicate that difficulties can also arise when under stress in oral situations. This is apparently due to the nature of the oral (viva) assessment being a pressurised assessment situation, in the knowledge that time is one of the key considerations. Jessica's Educational Assessment recommended that she should not be put under time pressure, nor pressurised into making quick decisions. This emphasises a key challenge for a person with dyslexia in tertiary education, and creates an opportunity for the LA to work with such a student on developing tools and strategies to help to deal with the kind of pressure Jessica was inevitably experiencing. The benefit of gaining speaking skills is in addition to developing resilience, through increased self-efficacy, and cultivating behaviours to reduce stress (Overton, 2005; Burdon, 2005). As previously mentioned, these strategies could also benefit many other students, as fear of public speaking is significant for many.

This research project supports the findings in Styles et al. (2018) that disclosure of dyslexia and provision for alternative assessments can support students in positive ways. This can be a whole-of-institution response based on quality information about dyslexia, such as disclosure for students on placement, in order to maximise their effectiveness, as supported by McPheat (2014). In relation to positive dyslexia (Nicolson, 2013) and strengths-based approaches, the benefits of finding out one's dyslexia profile, and being given relevant tools and information, can create lifelong improvements. Goldberg et al. (as cited in McPheat, 2014) identified the following attributes in order for a person with dyslexia to achieve success (p.46):

- self-awareness of one's disability or abilities

- social economic and political engagement

- determination to direct action of learning

- realistic goal setting

- good support structures

- good coping strategies. 
In the strengths-based literature, a wellness approach is seen as an active process of standing up against adversity (Jones-Smith, 2014; Ward \& Reuter, 2011), such as when a student fails an assessment. It is part of the Learning Advisor's role to empower students to learn from this, and turn failure into success.

This case study has created a narrative around the journey for one student, who, in various ways, embodied the above attributes. While Jessica may have been initially in denial and reluctant to meet with the Learning Advisor, over time she came to actively explore the links between dyslexia and her difficulties with oral skills, and was curious to know about and overcome the specific nature of her learning difficulties, through using the support networks available to her. The nature of her success may also have been aided by increasing maturity over her years of study.

\section{Conclusion}

There is a need to expand institutional processes to support the increasing numbers of students identified as having dyslexia, processes that may benefit all learners. Radloff (2006) calls for a university-wide approach to developing effective learners, and the report by Ako Aotearoa (Styles et al., 2018) outlines many ways in which the whole institution can support learners with dyslexia. LAs are one small but important part of the support network that may be available. Consequently, students with dyslexia may be helped by a Learning Advisor with the tools to develop self-knowledge and stress reduction, along with the language and communication skills required to effectively undertake oral assessments.

Learning Advisors, depending on the formulation of their service within their own institutions, should increasingly consider working with dyslexic students as part of their core responsibility. This work can be effective when delivered as individual consultations. Learning Advisors may need to develop specialist skills to work with dyslexic students in personal and creative ways. They should consider close liaison with disability support services, and advocate with subject lecturers to help to interpret and implement the needs of the students, especially recommendations from formal educational assessments. When this information is shared, with the student's permission, then departmental staff may be able to 
make more informed decisions regarding assessment practices, and Learning Advisors may enhance institutional knowledge about their roles.

There have been many other instances when the researcher has intuitively felt that she was a key contributor to students' success. This case study may not be generalisable to those other instances; however, taking the opportunity to probe the thoughts, feelings and perspectives of one student has led to certainty that, in this one case at least, the Learning Advisor's impact was demonstrable. The project helps to illustrate the wide range of tools that may be utilised when Learning Advisors assist learners with diverse needs. 


\section{References}

Ako Aotearoa and Primary ITO. (n.d.). Supporting adult dyslexics in tertiary education and training [Resource handbook]. Wellington, New Zealand: Author.

Anderson, J., \& Shepherd, J. (2006). 'Well said': Integrating language, learning and assessment to enhance student performance in design presentations. In G. Grigg, \& C. Bond (Eds.), Supporting learning in the $21^{\text {st }}$ century: Proceedings of the 2005 Annual International Conference of the Association of Tertiary Learning Advisors of Aotearoa/New Zealand (ATLAANZ) (pp.101-114). Auckland, New Zealand: ATLAANZ.

Blakemore, S., \& Frith, U. (2005). The learning brain: Lessons for education. Oxford, UK: Blackwell.

Blundell, S. (2006, August 12-18). Lost for words. New Zealand listener 204 (3457). Retrieved from http://www.listener.co.nz/issue/3457/features/6769/lost_for_words.html;jsessionid=E9

Bourke, R. (2015). Liberating the learner through self-assessment. Cambridge Journal of Education. doi: 10.1080/0305764X.2015.1015963

Burden, R. (2005). Dyslexia and self-concept: Seeking a dyslexic identity. London,UK: Whurr.

Cameron, C. (2018). Tertiary learning advisors in Aotearoa/New Zealand: Identity and opportunity (Special Issue). ATLAANZ Journal, 3: 1-80.

Cameron, C. (2012). Association of Tertiary Learning Advisors of Aotearoa New Zealand (ATLAANZ) professional practice document. Retrieved from http://docs.google.com/viewer?a=v\&pid=sites\&srcid=ZGVmYXVsdGRvbWFpbnxhdG xhYW56fGd40jNkNDExNTc1NDJjYmQONDI

Cameron, C., \& Catt, C. (2014). Learning Centre practice in Aotearoa/ New Zealand: Preliminary report. In H. Martin \& M. Simkin (Eds), Hikana te manuka: Learning connections in a changing environment: Proceedings of the 2013 Annual International Conference of the Association of Tertiary Learning Advisors of Aotearoa/ New Zealand (ATLAANZ) (pp.1-18). Napier, New Zealand: ATLAANZ.

Carter, S., Datt, A., \& Donald, C. (2012). The pedagogy and practice of elearning: Looking back to redirect the flow. In M. Protheroe (Ed.), Navigating the river: Proceedings of the 2011 Annual International Conference of the Association of Tertiary Learning Advisors of Aotearoa New Zealand (ATLAANZ), (pp. 21-36). Auckland: ATLAANZ.

Dennison, P., \& Dennison, G. (1989). Brain Gym: Teacher's edition revised. Ventura, CA: EduKinesthetics.

Dymock, S., \& Nicholson, T. (2012). Dyslexia decoded: What it is, what it isn't, and what you can do about it. Auckland, New Zealand: Dunmore.

Gao, X., and Reid, K. (2015). "What we do in the shadows": Evaluating the one-to-one tertiary learning advice consultation. Association of Tertiary Learning Advisors Aotearoa/New Zealand (ATLAANZ) Journal, 1, 34-53. 
Golding, C., Adam, L., Scott, C., Acheson, C., Johnson, K., Brook, P... Kumar, V. (2015). Fix, build, diagnose or guide? Evaluating the metaphors for learning advisors. The Association of Tertiary Learning Advisors Aotearoa/New Zealand (ATLAANZ)1.

Hammond, K. (2014). Presentation skills in changing environments. In H. Martin \& M. Simkin (Eds.), Hikana te Manuka! Learning connections in a changing environment: Proceedings of the 2013 Annual International Conference of the Association of Tertiary Learning Advisors of Aotearoa/ New Zealand (ATLAANZ) (pp.53-64). Napier, New Zealand: ATLAANZ.

Hammond, M., \& Wellington, J. (2013). Research methods: The key concepts. London, UK: Routledge.

Hargreaves, S. (Ed.). (2012). Study skills for students with dyslexia. London, UK: Sage.

Hughes, R. (2002). Teaching and researching speaking. Harlow, UK: Pearson.

Jamieson, C., \& Morgan, E. (2008). Managing dyslexia at university. London, UK: Routledge.

Jones-Smith, E. (2014). Strengths-based therapy: Connecting theory, practice and skills. London, UK: Sage.

McPheat, C. (2014). Experience of nursing students with dyslexia on clinical placement. Nursing Standard 28(41), 44-49.

Moody, S. (2004). Dyslexia: A teenager's guide. London: Vermilion.

Mortimore, T., \& Crozier, W. (2007). Dyslexia and difficulties with study skills in higher education. Studies in Higher Education 31(2). doi:10.1080/03075070600572173

Nicolson, R. (2013, May 20). Positive dyslexia: Dyslexia and talent. [Video file]. Retrieved from www.youtube.com/watch?v=XqmSMvkBPmQ

National Centre for Vocational Education Research (NCVER). (2015). Good practice guide: Supporting tertiary students with a disability or mental illness. Adelaide, Australia: Author.

Overton, A. (2005). Stress less: Make stress work for you not against you. Auckland, New Zealand: Random House.

Radloff, A. (2006). Supporting student learning in the $21^{\text {st }}$ century university: What's the job and whose job is it? In G. Grigg \& C. Bond (Eds), Supporting learning in the $21^{\text {st }}$ century: Proceedings of the 2005 Annual International Conference of the Association of Tertiary Learning Advisors Aotearoa/ New Zealand (ATLAANZ) (pp.2-17). Dunedin, New Zealand: ATLAANZ.

Scott, G. (2017). "Right” assessment. Retrieved from http://flipcurric.edu.au/about143/overview-of-the-six-keys/right-assessment

Seidman, I. (2013). Interviewing as qualitative research: A guide for researchers in education and the social sciences. New York: Teachers College Press. 
Seligman, M. (2002). Authentic happiness: Using the new positive psychology to realize your potential for lasting fulfilment. New York, NY: Free Press.

Simpson, O. (2002). Supporting students in online, open and distance learning ( $\left.2^{\text {nd }} \mathrm{ed}.\right)$. London, UK: Kogan Page.

Smith, R. (1982). Learning how to learn: Applied theory for adults. Milton Keynes, UK: Open University.

Stanton, R. (2007). Shifting paradigms: One to one consultations with English language learners in a tertiary learning centre. Scope Flexible Learning (1), 24-33.

Stanton, R., \& Wilson, L. (2013). Discovering authentic voice: An expressive arts therapy exploration of therapeutic voice work. ANZJAT Australian and New Zealand Journal of Arts Therapy, 8(1), 27-37.

Styles, M., Farrell, M., Peterson, L., Mik-Dekker, M., Agnew, L., Boss, D., Silvester, M., \& Borren, H. (2018). Evaluating the effectiveness of support interventions for adult dyslexic learners in New Zealand's multiple learning environments. Wellington, New Zealand: Ako Aotearoa. Retrieved from https://ako.ac.nz/knowledgecentre/interventions-for-learners-withdyslexia/report-evaluating-the-effectiveness-ofsupport-interventions-for-adultdyslexic-learners/

Tamblin, L., \& Ward, P. (2006). The smart study guide: Psychological techniques for student success. Oxford, UK: Blackwell.

Tummers, N. (2013). Stress management: A wellness approach. Torrens Park, South Australia: Human Kinetics.

Tunmer, W., \& Chapman, J. (2005). Students with learning difficulties and reading problems In D. Fraser, R. Moltzen and K. Ryba (Eds), Learners with special needs in Aotearoa New Zealand (pp 244-268). Southbank, Victoria: Dunmore Press.

Ward, C., \& Reuter, T. (2011). Strength-centered counselling: Integrating postmodern approaches and skills with practice. Thousand Oaks, CA: Sage.

Yin, R. K. (2003). Case study research design and methods. London, UK: Sage.

Yin, R. K. (2011). Qualitative research from start to finish. London, UK: Guilford Press. 